\title{
Evolving thermostability in mutant libraries of ligninolytic oxidoreductases expressed in yeast
}

Eva García-Ruiz ${ }^{1,2}$, Diana Maté ${ }^{1}$ Antonio Ballesteros ${ }^{1}$, Angel T Martinez $^{2}$, Miguel Alcalde ${ }^{1 *}$

\begin{abstract}
Background: In the picture of a laboratory evolution experiment, to improve the thermostability whilst maintaining the activity requires of suitable procedures to generate diversity in combination with robust highthroughput protocols. The current work describes how to achieve this goal by engineering ligninolytic oxidoreductases (a high-redox potential laccase -HRPL- and a versatile peroxidase, -VP-) functionally expressed in Saccharomyces cerevisiae.

Results: Taking advantage of the eukaryotic machinery, complex mutant libraries were constructed by different in vivo recombination approaches and explored for improved stabilities and activities. A reliable high-throughput assay based on the analysis of $T_{50}$ was employed for discovering thermostable oxidases from mutant libraries in yeast. Both VP and HRPL libraries contained variants with shifts in the $T_{50}$ values. Stabilizing mutations were found at the surface of the protein establishing new interactions with the surrounding residues.

Conclusions: The existing tradeoff between activity and stability determined from many point mutations discovered by directed evolution and other protein engineering means can be circumvented combining different tools of in vitro evolution.
\end{abstract}

\section{Background}

During the last couple of decades, thermostability has been considered by many as a key feature in terms of protein robustness, evolvability and catalytic function [1-4]. From a practical point of view, the engineering of thermo-tolerant biocatalysts is highly desirable since transformations at high temperatures intrinsically supply a box-set of key biotechnological advantages (higher entropies -better reaction yields-, solubilisation of hydrophobic compounds or low levels of microbial sidecontamination, among others). Besides, thermostable enzymes are typically tolerant to many other harsh conditions often required in industry, such as the presence of organic co-solvents, extreme $\mathrm{pHs}$, high salt concentrations, high pressures, etc $[5,6]$. Few exceptions aside $[7,8]$, the discovery of stabilizing mutations is not always straightforwardly accomplished without significant drops in turnover rates [9]. Most of these mutations, which establish new interactions by salt bridges, hydrogen bonds, hydrophobic contacts or even disulfide bridges, are placed either at the protein surface or in internal

\footnotetext{
* Correspondence: malcalde@icp.csic.es

${ }^{1}$ Department of Biocatalysis, Institute of Catalysis, CSIC, 28049 Madrid, Spain
}

cores pursuing the tightly packing of the tertiary protein structure in order to prevent unfolding and denaturation under extreme environments [10]. On the contrary, improvements in activity are generally accomplished by introducing beneficial but destabilizing mutations in hot regions for catalysis (substrate binding sites, channels of access to the active pockets) although sometimes distant mutations can also vary the catalytic function by altering the dynamics and geometry in the protein scaffold [3]. There are several examples in literature about the stabilization of enzymes by directed evolution or rational design but unfortunately, main constraints still remain from the lack of appropriate methods to recreate diversity in conjunction with reliable screening strategies, especially if one wants to surpass the existing tradeoff between activity and thermostability for many single residue substitutions [10-20].

Among the enzymes forming the ligninolytic system of white-rot fungi (i.e. involved in lignin biodegradation), high redox potential laccases HRPL (EC 1.10.3.2) and peroxidases, including versatile peroxidases (VP; EC 1.11.1.14) are outstanding biocatalysts finding potential applications in paper pulp bleaching and functionalization, 
bioremediation, organic synthesis, food and textile industries, nanobiodevice construction and more [21-23]. Indeed, HRPL can oxidize dozens of different compounds releasing water as the only by-product and in the presence of redox mediators (diffusible electron carriers from natural or synthetic sources) their substrates specificities are further expanded $[24,25]$. On the other hand, VP (with redox potential above $+1000 \mathrm{mV}$ ) shares the catalytic features of lignin and manganese peroxidase in terms of substrate specificity, together with the ability to oxidize phenols and dyes characteristic of low redox-potential peroxidases. Indeed, the presence of different catalytic sites in a small and compact protein structure (around 300 amino acids) makes VP an ideal platform for laboratory evolution strategies $[23,26,27]$.

Here, we have employed these two enzymatic systems as departure points to improve their protein thermostability by directed evolution. VP and HRPL were functionally expressed in yeast and mutant libraries were constructed combining several methodologies of in vitro evolution to guarantee the library complexity, favoring the selection of optimal crossover events or the discovery of beneficial mutations. Highly functional/soluble expressed mutants were stressed under high temperatures and explored for activity and stability. The analysis of the data from screening (ratio residual activity/initial activity in combination with the $\mathrm{T}_{50}$ values) enabled us to discover stabilizing mutations in both systems.

\section{Materials and methods}

HRPL from basidiomycete PM1 [28] (PM1-7H2 mutant) and VP from Pleurotus eryngii (10C3, 6B1, 13E4, 6E7 and 11F3 mutants of the allelic variant VPL2, GenBank AF007222) were used as parent types for library construction. Both systems are from previous engineering work by several rounds of directed evolution in S. cerevisiae including the replacement of their original native signal sequences by the alpha factor prepro-leader, ([29] and unpublished material). ABTS (2,2'-azino-bis(3-ethylbenzothiazoline-6-sulfonic acid)), bovine haemoglobine, Taq polymerase and the $S$. cerevisiae transformation kit were purchased from Sigma-Aldrich (Madrid, Spain). The E. coli XL2-blue competent cells and the Genemorph Random mutagenesis kit were from Stratagene (La Jolla, CA, USA). The protease deficient $S$. cerevisiae strain BJ5465 was from LGCPromochem (Barcelona, Spain). The uracil independent and ampicillin resistance shuttle vector pJRoC30 was obtained from the California Institute of Technology (CALTECH, USA), while the zymoprep yeast plasmid miniprep kit, zymoclean gel DNA recovery kit, and the DNA clean and concentrator TM-5 kit were all from Zymo Research (Orange, CA). NucleoSpin Plasmid kit was purchased from Macherey-Nagel (Germany) and the restriction enzymes $B a m H I$ and XhoI were from New
England Biolabs (Hertfordshire, UK). All chemicals were of reagent-grade purity.

\section{Culture media}

Minimal medium contained $100 \mathrm{~mL} \mathrm{6.7 \%} \mathrm{sterile} \mathrm{yeast}$ nitrogen base, $100 \mathrm{~mL} 19.2 \mathrm{~g} / \mathrm{L}$ sterile yeast synthetic drop-out medium supplement without uracil, $100 \mathrm{~mL}$ sterile $20 \%$ raffinose, $700 \mathrm{~mL} s d d \mathrm{H}_{2} \mathrm{O}$ and $1 \mathrm{~mL} 25 \mathrm{~g} / \mathrm{L}$ chloramphenicol. YP medium contained 10 g yeast extract, $20 \mathrm{~g}$ peptone and $d d \mathrm{H}_{2} \mathrm{O}$ to $650 \mathrm{~mL}$. Expression medium contained $720 \mathrm{~mL} \mathrm{YP,} 67 \mathrm{ml} 1 \mathrm{M} \mathrm{KH}_{2} \mathrm{PO}_{4}$ pH 6.0 buffer, $111 \mathrm{~mL} \mathrm{20 \%} \mathrm{galactose,} 1 \mathrm{ml} 25 \mathrm{~g} / \mathrm{L}$ chloramphenicol and $d d \mathrm{H}_{2} \mathrm{O}$ to $1000 \mathrm{~mL}$. For HRPL the expression medium was supplemented with $2 \mathrm{mM} \mathrm{CuSO}_{4}$ and $25 \mathrm{~g} / \mathrm{L}$ ethanol. For VP the expression medium was supplemented with $100 \mathrm{mg} / \mathrm{L}$ bovine haemoglobine. YPD solution contained 10 g yeast extract, $20 \mathrm{~g}$ peptone, $100 \mathrm{~mL} 20 \%$ sterile glucose, $1 \mathrm{ml} 25 \mathrm{~g} / \mathrm{L}$ chloramphenicol and $d d \mathrm{H}_{2} \mathrm{O}$ to 1000 $\mathrm{mL}$. SC drop-out plates contained $100 \mathrm{~mL}$ 6.7\% sterile yeast nitrogen base, $100 \mathrm{~mL} 19.2 \mathrm{~g} / \mathrm{L}$ sterile yeast synthetic drop-out medium supplement without uracil, $20 \mathrm{~g}$ bacto agar, $100 \mathrm{~mL} 20 \%$ sterile glucose, $1 \mathrm{~mL} 25 \mathrm{~g} / \mathrm{L}$ chloramphenicol and $d d \mathrm{H}_{2} \mathrm{O}$ to $1000 \mathrm{ml}$.

\section{Library construction for laboratory evolution General aspects}

Unless otherwise specified, PCR fragments were cleaned, concentrated and loaded onto a low melting point preparative agarose gel and purified using the Zymoclean gel DNA recovery kit (Zymo Research). PCR products were cloned under the control of the Gal 10 promoter of the expression shuttle vector pJRoC30, replacing the corresponding parental gene in pJRoC30. To remove the parental gene, the pJRoC30 plasmid was linearized (with XhoI and BamHI for HRPL- and VP-libraries). Linearized vector was concentrated and purified as described above for the PCR fragments.

Mutagenic StEP (Staggered Extension Process) followed by in vivo DNA shuffling and IvAM (In vivo Assembly of Mutant libraries with different mutational spectra) were used to create the VP and HRPL libraries, respectively, as described below.

\section{VP Library: mutagenic StEP + in vivo DNA shuffling}

10C3, 6B1, 13E4, 6E7 and 11F3 VP-mutants were used as parental types. StEP was performed as reported elsewhere [30] with some modifications. In order to favor random mutagenesis during StEP, Taq DNA-polymerase was employed for the PCR reaction along with low concentration of templates to promote the introduction of point mutations during the amplification. The primers used were: RMLN-sense (5'-CCTCTAATACTTTAACGTCAAGG-3') and RMLC-antisense (5'-GGGAGGGCGTGAATGTAAGC-3'). For the in vivo ligation, overhangs of $40 \mathrm{bp}$ and $66 \mathrm{bp}$ that were homologous to 
linearized vector were designed. PCR reactions were performed in a final volume of $50 \mu \mathrm{L}$ containing $90 \mathrm{nM}$ RMLN, 90 nM RMLC, 0.3 mM dNTPs, 3\% dimethylsulfoxide (DMSO), $0.05 \mathrm{U} / \mu \mathrm{L}$ of Taq polymerase (Sigma), $1.5 \mathrm{mM} \mathrm{MgCl}_{2}$ and $0.1 \mathrm{ng} / \mu \mathrm{L}$ of $10 \mathrm{C} 3,6 \mathrm{~B} 1,13 \mathrm{E} 4,6 \mathrm{E} 7$ and 11F3 DNA-template mixture. StEP was carried out using a gradient thermocycler (Mycycler, Biorad, USA). The thermal cycling parameters were as follows: $95^{\circ} \mathrm{C}$ for $5 \mathrm{~min}$ ( $1 \mathrm{cycle}), 94^{\circ} \mathrm{C}$ for $30 \mathrm{~s}$ and $55^{\circ} \mathrm{C}$ for $20 \mathrm{~s}(90$ cycles). Purified PCR products were further recombined by in vivo DNA-shufflling [31]. PCR mutated/recombined products were mixed equimolarly (160 ng of each product) and transformed along with linearized vector (ratio PCR product:vector, 4:1) into competent cells using the yeast transformation kit (Sigma). A mutant library of $\sim 2000$ clones was explored.

\section{HRPL Library: IVAM}

IVAM ( 1300 clones) was performed as reported elsewhere [32] with some modifications. HRPL PM1-7H2 mutant was used as parent type. Mutagenic PCR was carried out using the following thermal cycling parameters: $95^{\circ} \mathrm{C}$ for $2 \mathrm{~min}(1 \mathrm{cycle}), 94^{\circ} \mathrm{C}$ for $0.45 \mathrm{~min}, 53^{\circ} \mathrm{C}$ for 0.45 $\min , 74^{\circ} \mathrm{C}$ for $3 \mathrm{~min}$ ( 28 cycles), $74^{\circ} \mathrm{C}$ for $10 \mathrm{~min}(1$ cycle). For the Taq library the concentrations of each ingredient in $50 \mu \mathrm{L}$ final volume were as follows: $90 \mathrm{nM}$ RMLN; $90 \mathrm{nM}$ RMLC; $0.1 \mathrm{ng} / \mu \mathrm{L}$ HRPL template; 0.3 mM dNTPs (0.075 mM each); 3\% DMSO; $1.5 \mathrm{mM}$ $\mathrm{MgCl}_{2} ; 0.01 \mathrm{mM} \mathrm{MnCl}$ and $0.05 \mathrm{U} / \mu \mathrm{L}$ Taq polymerase. For the Mutazyme library the concentrations of each reagent in $50 \mu \mathrm{L}$ final volume were as follows: $370 \mathrm{nM}$ RMLN; 370 nM RMLC, $40 \mathrm{ng} / \mu \mathrm{L}$ HRPL template; 0.8 mM dNTPs; 3\% DMSO; and $0.05 \mathrm{U} / \mu \mathrm{L}$ Mutazyme DNA polymerase. Taq/ $\mathrm{MnCl}_{2}$ and Mutazyme libraries were equimolarly mixed and transformed along with linearized vector (ratio equimolar library:vector, 8:1) into competent $S$. cerevisiae cells as described above.

\section{High-throughput thermostability assay}

Individual clones were picked and cultured in 96-well plates (Sero-well, Staffordshire, UK) containing $50 \mu \mathrm{L}$ of minimal medium per well. In each plate, column number 6 was inoculated with standard (parental HRPL or VP), and one well (H1-control) was either not inoculated for HRPL libraries or inoculated with untransformed S. cerevisiae cells for VP-libraries. Plates were sealed to prevent evaporation and incubated at $30^{\circ} \mathrm{C}, 225 \mathrm{RPM}$ and $80 \%$ relative humidity in a humidity shaker (MinitronINFORS, Biogen, Spain). After 48 h, $160 \mu \mathrm{L}$ of expression medium were added to each well, and the plates were incubated for $24 \mathrm{~h}$. The plates (master plates) were centrifuged (Eppendorf 5810R centrifuge, Germany) for 5 $\min$ at $3000 \times g$ at $4{ }^{\circ} \mathrm{C}$ and $20 \mu \mathrm{L}$ of supernatant was transferred from the master plate with the help of a robot (Liquid Handler Quadra 96-320, Tomtec, Hamden, CT,
USA) onto the replica plate. Subsequently, $180 \mu \mathrm{L}$ of stability buffer (10 mM sodium tartrate buffer $\mathrm{pH} 5.1$ for VP-library and $10 \mathrm{mM}$ Britton and Robinson buffer $\mathrm{pH}$ 6.0 for HRPL-library) were added to each replica and briefly stirred. Replica plate was duplicated with the help of the robot by transferring $50 \mu \mathrm{L}$ of mixture to a thermocycler plate (Multiply PCR plate without skirt, neutral, Sarstedt, Germany) and $20 \mu \mathrm{L}$ to the initial activity plate. Thermocycler plates were sealed with thermoresistant film (Deltalab, Spain) and incubated at the corresponding temperature using a thermocycler (MyCycler, Biorad, USA). Incubation took place for $10 \mathrm{~min}$ (so that the assessed activity was reduced $2 / 3$ of the initial activity). Afterwards, thermocycler plates were placed on ice for $10 \mathrm{~min}$ and further incubated for $5 \mathrm{~min}$ at room temperature. $20 \mu \mathrm{L}$ of supernatants were transferred from both thermocycler and initial activity plates to new plates to estimate the initial activities and residual activities values by adding ABTS containing specific buffers. For VP-libraries $180 \mu \mathrm{L}$ of $100 \mathrm{mM}$ sodium tartrate buffer $\mathrm{pH} 3.5$ containing $2 \mathrm{mM}$ ABTS and $0.1 \mathrm{mM} \mathrm{H}_{2} \mathrm{O}_{2}$ were added to each plate. For HRPL-libraries $180 \mu \mathrm{L}$ of 100 $\mathrm{mM}$ sodium acetate buffer $\mathrm{pH} 5.0$ containing $3 \mathrm{mM}$ ABTS were added. Plates were stirred briefly and the absorption at $418 \mathrm{~nm}\left(\varepsilon_{\mathrm{ABTS}}{ }^{\cdot+}=36,000 \mathrm{M}^{-1} \mathrm{~cm}^{-1}\right)$ was recorded in the plate reader (SPECTRAMax Plus 384, Molecular Devices, Sunnyvale, CA). The plates were incubated at room temperature until a green color developed, and the absorption was measured again. The same experiment was performed for both the initial activity plate and residual activity plate. Relative activities were calculated from the difference between the absorption after incubation and that of the initial measurement normalized against the parental type in the corresponding plate. Thermostability values came from the ratio between residual activities and initial activities values. To rule out false positives, two consecutive rescreenings were carried out according to the protocol previously reported [33] with some modifications. A third rescreening was incorporated to calculate the $\mathrm{T}_{50}$ of selected mutants.

\section{First rescreening}

aliquots of $5 \mu \mathrm{L}$ of the best clones were removed from master plates to inoculate $50 \mu \mathrm{L}$ of minimal media in new 96-well plates. Columns 1 and 12 (rows $\mathrm{A}$ and $\mathrm{H}$ ) were not used to prevent the appearance of false positives. After $24 \mathrm{~h}$ of incubation at $30^{\circ} \mathrm{C}$ and $225 \mathrm{RPM}, 5$ $\mu \mathrm{L}$ were transferred to the adjacent wells and further incubated for $24 \mathrm{~h}$. Finally, $160 \mu \mathrm{L}$ of expression medium were added and plates were incubated for $24 \mathrm{~h}$. Accordingly, every single mutant was grown in 4 wells. Parent types were subjected to the same procedure (lane D, wells 7-11). Plates were assessed using the same protocol of the screening described above but including not 
only an endpoint assay but also a kinetic assay. In the ABTS kinetic assay, linear absorption increases over a wide range of enzyme concentration (1-20 $\mathrm{mU} / \mathrm{mL}$ ) allowing the estimation of initial rates.

\section{Second rescreening}

an aliquot from the wells with the best clones of first rescreening was inoculated in $3 \mathrm{~mL}$ of YPD and incubated at $30^{\circ} \mathrm{C}$ and $225 \mathrm{RPM}$ for $24 \mathrm{~h}$. Plasmids from these cultures were extracted (Zymoprep yeast plasmid miniprep kit, Zymo Research). As the product of the zymoprep was very impure and the concentration of extracted DNA was very low, the shuttle vectors were transformed into super-competent E. coli cells (XL2Blue, Stratagene) and plated onto LB-amp plates. Single colonies were picked and used to inoculate $5 \mathrm{~mL} \mathrm{LB}$ amp media and were grown overnight at $37^{\circ} \mathrm{C}$ and 225 RPM. Plasmids were then extracted (NucleoSpin ${ }^{\circledR}$ Plasmid kit, Macherey-Nagel, Germany). S. cerevisiae was transformed with plasmids from the best mutants and also with parent type. Five colonies of every single mutant were picked and rescreened as described above (using both end-point and kinetic assays).

\section{Third rescreening ( $T_{50}$ determination)}

fresh transformants of selected mutants and parent types were cultivated $(10 \mathrm{~mL})$ in $100 \mathrm{~mL}$ flask for VP and HRPL production. Supernatants were subjected to a thermostability assay to accurate estimate their $\mathrm{T}_{50}$ using 96/384 well gradient thermocyclers (Mycycler, Biorad, US). Appropriate dilutions of supernatants were prepared with the help of the robot in such a way that aliquots of $20 \mu \mathrm{L}$ give rise to a linear response in kinetic mode. $50 \mu \mathrm{L}$ (from both selected mutants and parent types) were used for each point in the gradient scale. A temperature gradient profile ranging from 30 to $90^{\circ} \mathrm{C}$ was established. After $10 \mathrm{~min}$ of incubation, samples were removed and chilled out on ice for $10 \mathrm{~min}$. Afterthat, samples of $20 \mu \mathrm{L}$ were removed and incubated at room temperature for $5 \mathrm{~min}$. Finally, samples were subjected to the same ABTS-based colorimetric assay described above for the screening. Thermostabilities values were deduced from the ratio between the residual activities incubated at different temperature points and the initial activity at room temperature.

\section{Determination of thermostabilities in VP and HRPL parent types}

Thermostabilities of 7H2-HRPL and 10C3-VP mutants were assessed mimicking the growth conditions established for the screening assay as described above. Two 96 well-plates containing $50 \mu \mathrm{L}$ minimal media were inoculated with $7 \mathrm{H} 2$ and $10 \mathrm{C} 3$ respectively and cultivated until reaching functional expression following the conditions used for the assay. Afterwards, supernantants of $7 \mathrm{H} 2$ and $10 \mathrm{C} 3$ were pooled and employed to estimate their respective thermostabilities with the gradient thermocycler. The gradient of temperature was set at the following points $\left(\mathrm{in}^{\circ} \mathrm{C}\right)$ : 30.0, 31.7, 34.8, 39.3, 45.3, 49.9, 53.0, 55.0, 56.8, 59.9, 64.3, 70.3, 75.0, 78.1 and 80 for the VP mutant and $35.0,36.7,39.8,44.2,50.2,54.9$, $58.0,60.0,61.1,63.0,65.6,69.2,72.1,73.9,75.0,76.2$, $78.0,80.7,84.3,87.1,89.0$ and 90.0 for the HRPL mutant. The protocol followed the general rules described for the third re-screening.

\section{DNA sequencing}

Plasmid-containing variant HRPL and VP genes were sequenced by using a BigDye Terminator v 3.1 Cycle Sequencing Kit. Primers were designed with Fast-PCR software (University of Helsinki, Finland). Primers used for VP variants were: RMLN; 3R-direct (5'-GTTCCATCATCGCGTTCG-3'); 5F-reverse (5'-GGATTCCTTTCTTCTTGG-3') and RMLC. For HRPL primers were: RMLN; PM1FS (5'-ACGACTTCCAGGTCCCTGACCAAGC-3'); PM1RS (5'-TCAATGTCCGCGTTCGCAGGGA-3') and RMLC.

\section{Protein modelling}

We carried out a search in the Protein Data Bank for proteins with known structural homology to laccase PM1. The most similar protein to PM1 was a laccase from Trametes trogii (crystal structure solved with a resolution of $1.58 \AA$ ), showing 97\% sequence identity (PDB id: 2hrgA) [34]. A model from the Swiss-Model protein automated modelling server was generated http://swissmodel.expasy.org/ and analyzed with DeepView/Swiss-Pdb Viewer.

\section{Results and discussion}

\section{Library construction}

VP and HRPL variants come from laboratory evolution approaches to be functionally expressed in Saccharomyces cerevisiae ([29] and unpublished material). Therefore, the array of variants used as starting points for enhancing thermostability, in principle only were going to harbor mutations which conferred higher secretion levels and/or better kinetics. Both VP and HRPL native signal peptides were replaced by the $\alpha$-factor pre-proleader to promote secretion in yeast [35]. Thus, the whole fusion proteins ( $\alpha$-VP and $\alpha$-HRPL) were subjected to directed evolution in order to enhance their functional expression; i.e. the accumulation of neutral and beneficial mutations took place both in the $\alpha$-factor pre-proleader as well as in mature protein. If high fidelity DNA recombination strategies are used, where only accumulated mutations recombine each other based on the number of crossovers generated in the protocol, it is highly likely that the discovery of thermostable variants become a complex task, since all these mutations have been 
unmasked from improvements in total activities; i.e. the sum of secretion levels plus the specific activity. Hence, we decided to tackle the library design by combining the already accumulated mutations with the generation of new ones randomly incorporated in the frame of mutagenic DNA recombination fashion approaches (Fig. 1). For the VP library the well known Staggered Extension
Process (StEP) [30] was slightly modified by decreasing templates concentration with the aim of provoking amplification mistakes by the Taq DNA-Polymerase which has a high intrinsic error rate because of the lack of 3'-5'proofreading exonuclease activity. The mutational rate was adjusted to 1-2 mutations per whole gene [36]. Afterwards, and instead of in vitro ligating the StEP

\section{A}

\section{Mutagenic StEP}

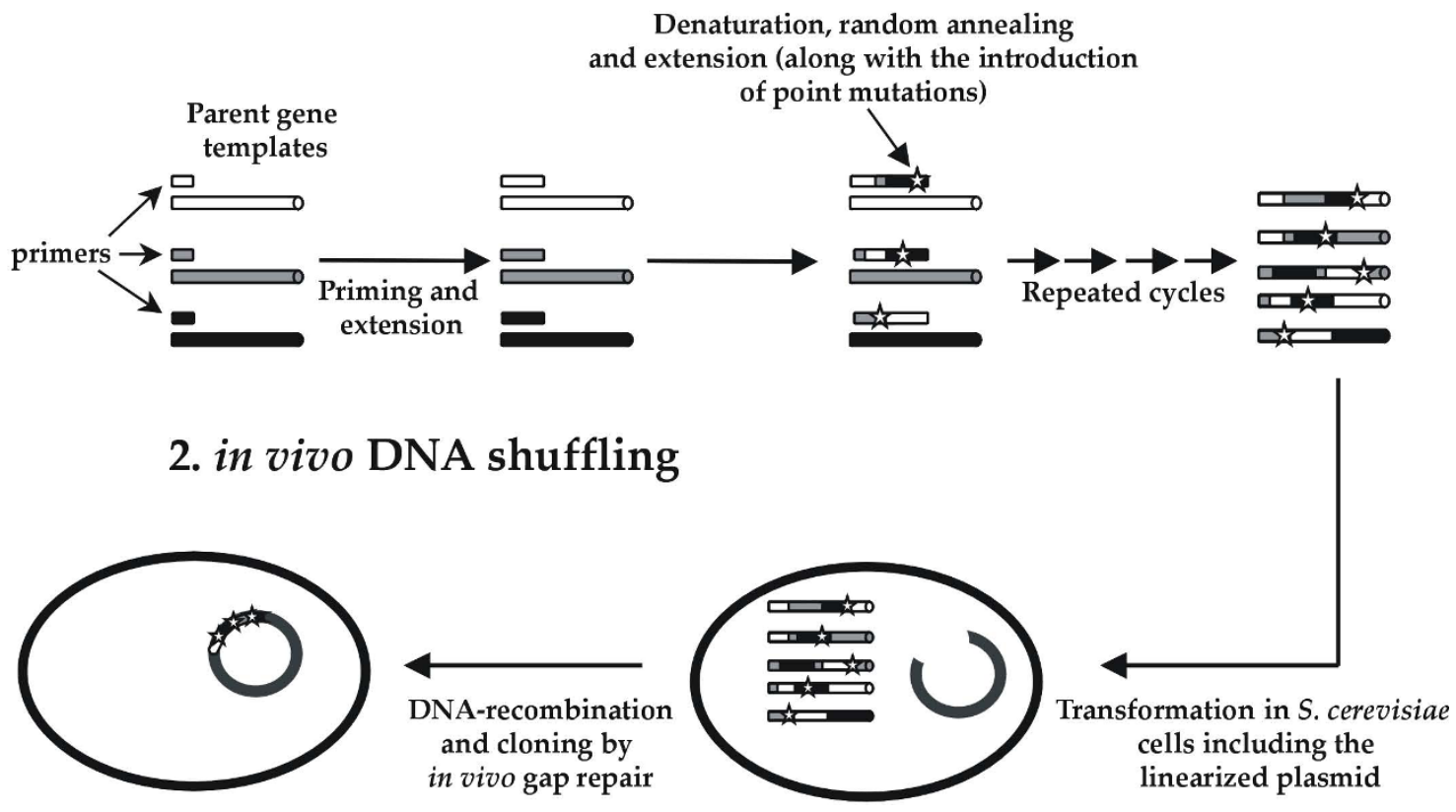

B

\section{in vivo assembly of mutant libraries (IvAM)}

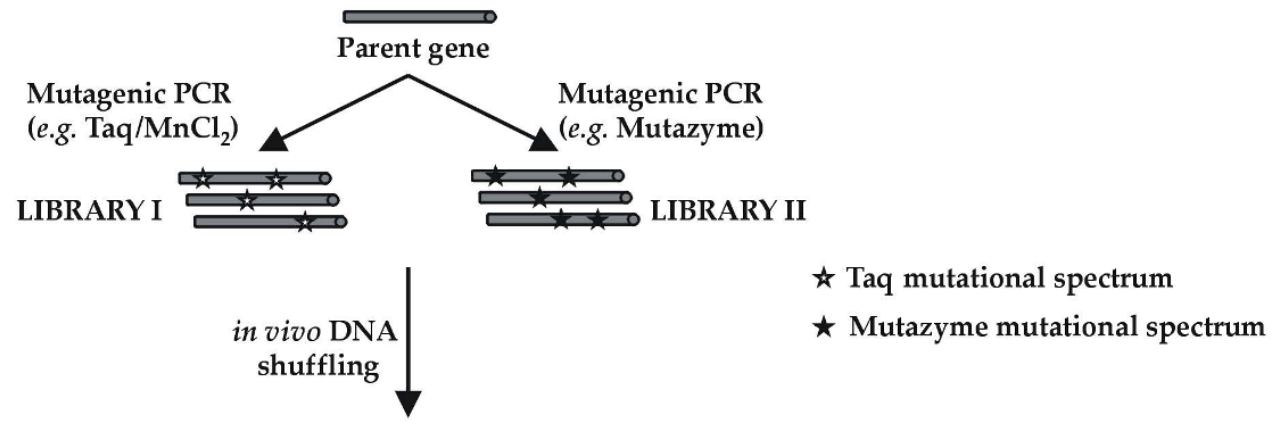

New mutational spectrum

Figure 1 schematic representation of methods employed for the construction of VP (A) and HRPL (B) mutant libraries. 
products with the linearized plasmid to give rise to individual autonomously replicating vectors as usually proceeds, we thought that might be interesting to further recombine the pool of mutagenized/crossover containing genes in an in vivo approach with the aim of expanding the library diversity. Thus, StEP products were further subjected to an in vivo DNA-shuffling process $[31,37,38]$ taking advantage of the high level of homologous recombination of $S$. cerevisiae apparatus as described in the Material \& Methods section. With this strategy, new crossover events were generated that otherwise hardly could be achieved by using conventional in vitro or in vivo recombination methods independently. In the case of HRPL library, the only starting template gene was subjected to the in vivo assembly of mutant libraries with different mutational spectrum (IvAM) [32], to guarantee the enrichment of the library in different mutational types and bias. With this simple approach, the homologous recombination, reparation and in vivo cloning of mutant genes along with their in vivo DNA-shuffling, in one single step were achieved.

\section{High-throughput screening assay}

ABTS was chosen as substrate for the screening assay since it has a reliable response, high sensitivity and hardly interferes with the main components of culture broth. Indeed, in our former works ABTS was validated in the frame of directed laccase evolution for several purposes [33,38-40]. However, the response of this substrate against the secreted VP mutants by $S$. cerevisiae was unknown and therefore we had to validate it before starting the thermostability studies. First, the relationship between absorbance and VP concentration was evaluated. Fresh transformants containing VP-10C3 mutant (the best parent type) were inoculated in a 96well plate, VP-10C3 was expressed and different volumes of supernatant were assessed. A linear behavior between the amount of VP and the response of the assay was found (Fig. 2A). The coefficient of variation for the ABTS in kinetic mode was 13\%, which is an acceptable value to study mutagenic libraries engineered for directed evolution experiments [9] (Fig. 2B).

For the thermostability assay, we first had to set the temperature under which the mutant libraries would be stressed. Accordingly, the two best parent types of both VP and HRPL libraries were tested in order to know their respective thermostabilities. Taking into account that micro-fermentation conditions (i.e. in 96 well plates) were far away from an ideal large-scale fermentation in terms of oxygen availability, surface stirring and length of incubation time, VP-10C3 and HRPL-7H2 mutants were produced under such a limited growth conditions and evaluated to obtain the closest real value of thermostability in the screening assay
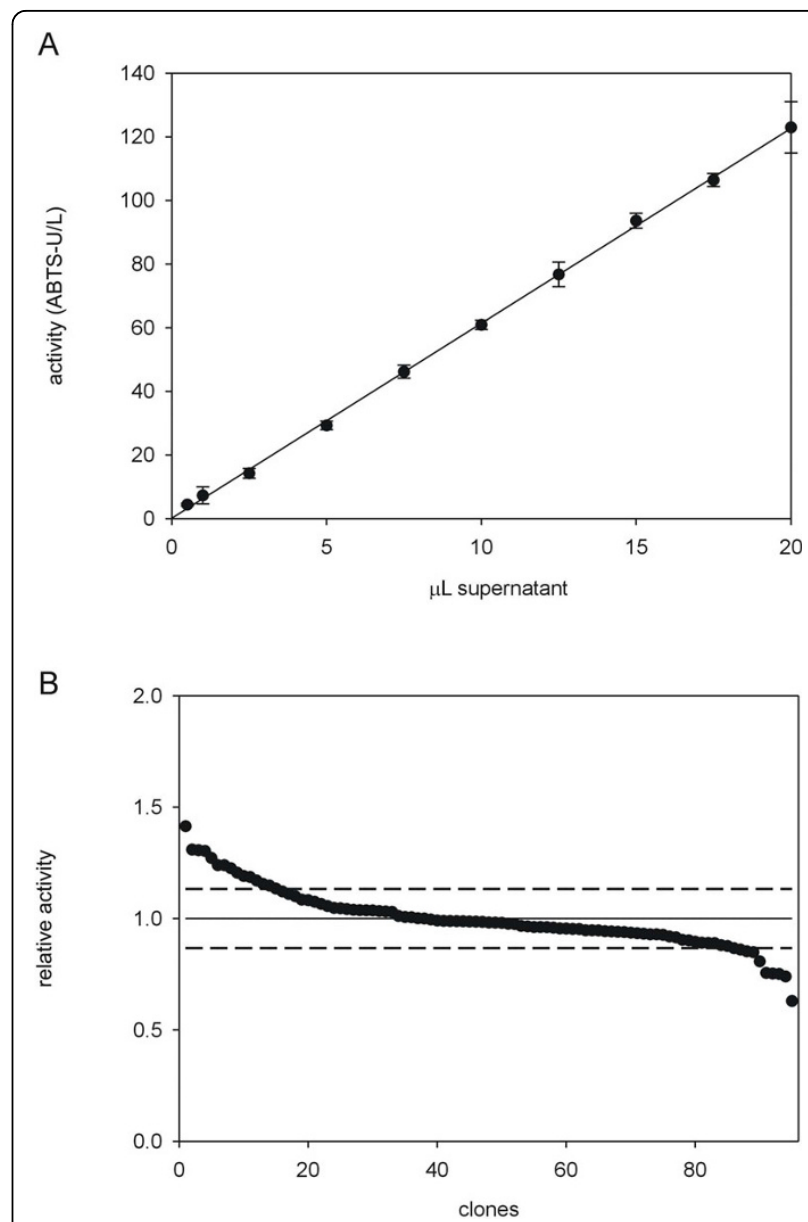

Figure 2 validation of the colorimetric assay for the VP-library A) Linearity of the assay. Each point represents the average of 8 experiments (8 wells). B) Activities of VP-10C3 plotted in descending order. Dashed lines indicate the variation coefficient of the assay. $S$. cerevisiae cells were transformed with pJRoC30-VP-10C3 and plated on SC dropout plates. Individual colonies were picked and inoculated in a 96 well-plate. The activities of the clones were evaluated from fresh supernatant preparations.

(further details in Material \& Methods section). In principle, an appropriate enzyme heat treatment for the screening is generally chosen so that the residual activity is about one-third of the initial activity [9]. At $60^{\circ} \mathrm{C}$ and $68^{\circ} \mathrm{C}, \mathrm{VP}-10 \mathrm{C} 3$ and HRPL-7H2 mutants kept c.a. $30 \%$ of their initial ABTS-activity values, and those temperatures were selected for the screening. At this point, it is important to highlight that both VP and HRPL libraries were functionally secreted by yeast, which made the development of the assay faster, reliable and simple since it was not necessary to include cell lysis steps, thus avoiding possible interferences with the complex lysate mixture. Besides, both VP and HRPL secretion levels were previously improved by several iterative rounds of directed evolution to provide: i) short incubations times for functional secretion 
$(24 \mathrm{~h})$ after protein induction that becomes essential for the episomal plasmid stability; and ii) a high level of activity in supernatants (getting measurements from kinetic mode in a few seconds with turnover rates ranging from 0.5 to 1 ABTS-Units $/ \mathrm{mL}$ ). Taking advantage of the high level of activity in the culture broth, supernatants of respective libraries were previously diluted in suitable corresponding stability buffers to correctly assess initial and residual activities (Fig. 3). The final values of thermostability came from the ratio of residual activity to initial activity (RA/IA) normalized with the corresponding parent type. The initial activity value reflected the total activity of the mutant and was highly useful to prevent the selection of mutants with improved stability by greatly reduced activity.

\section{Library analysis}

Under the above premises, two libraries of $\sim 2000$ clones were independently constructed and explored for VP and HRPL (Fig. 4). The estimated coefficients of variance for the landscapes of initial activity and residual activity were below $12 \%$. Three consecutive re-screens were incorporated to ensure the selection of mutant hits in protein function. Systematically, the best 50 clones retaining $\sim 0.7$ fold the activity of parent type and showing improvements in thermostability were selected and double rescreened from supernatants and new fresh transformants. Finally, best mutants were subjected to a third rescreen to estimate their $\mathrm{T}_{50}$; i.e. the transition midpoint of the inactivation curve of the protein as a function of temperature, which in our case was defined as the temperature at which the enzyme loses $50 \%$ of its activity following incubation for $10 \mathrm{~min}$.

The best four mutants of VP library, with significant improvements in their activities and/or thermostabilities, were sequenced (Fig. 5). These variants shared the common feature of incorporating 4 mutations (E37K, V160A, T184M and Q202L) accumulated round after round of evolution in the same mature protein. Interestingly, the best variant of activity (R4 mutant with $3180 \pm 30$ ABTSUnits/L) only contained the mentioned 4 mutations after 4 cycles of evolution. The remaining selected variants displayed a negative epistatic effect, i.e. the general combination of mutations is beneficial but at least one individual mutation is not, after incorporating new point mutations (with improvement ranging from 1.7 to 1.1

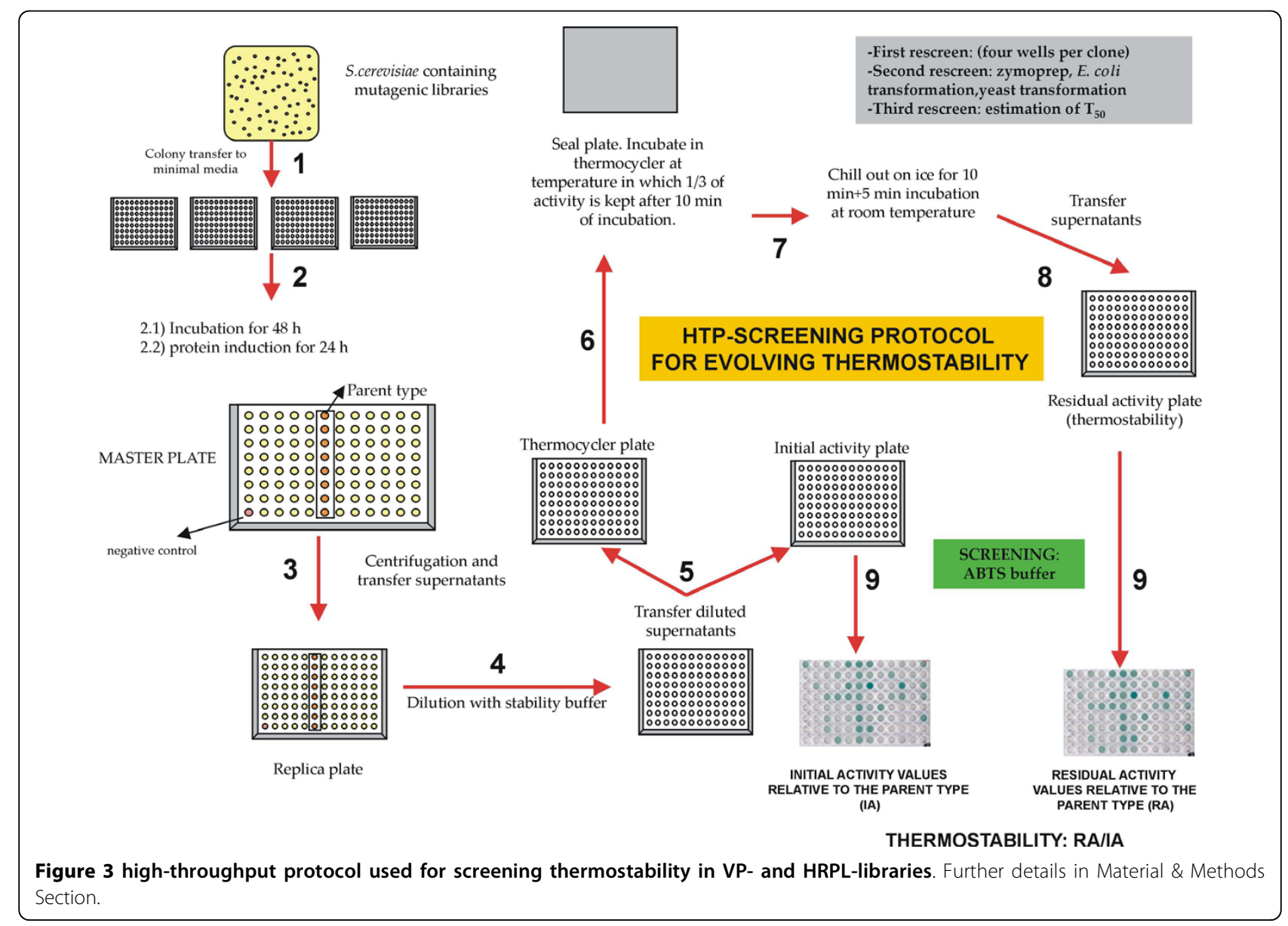




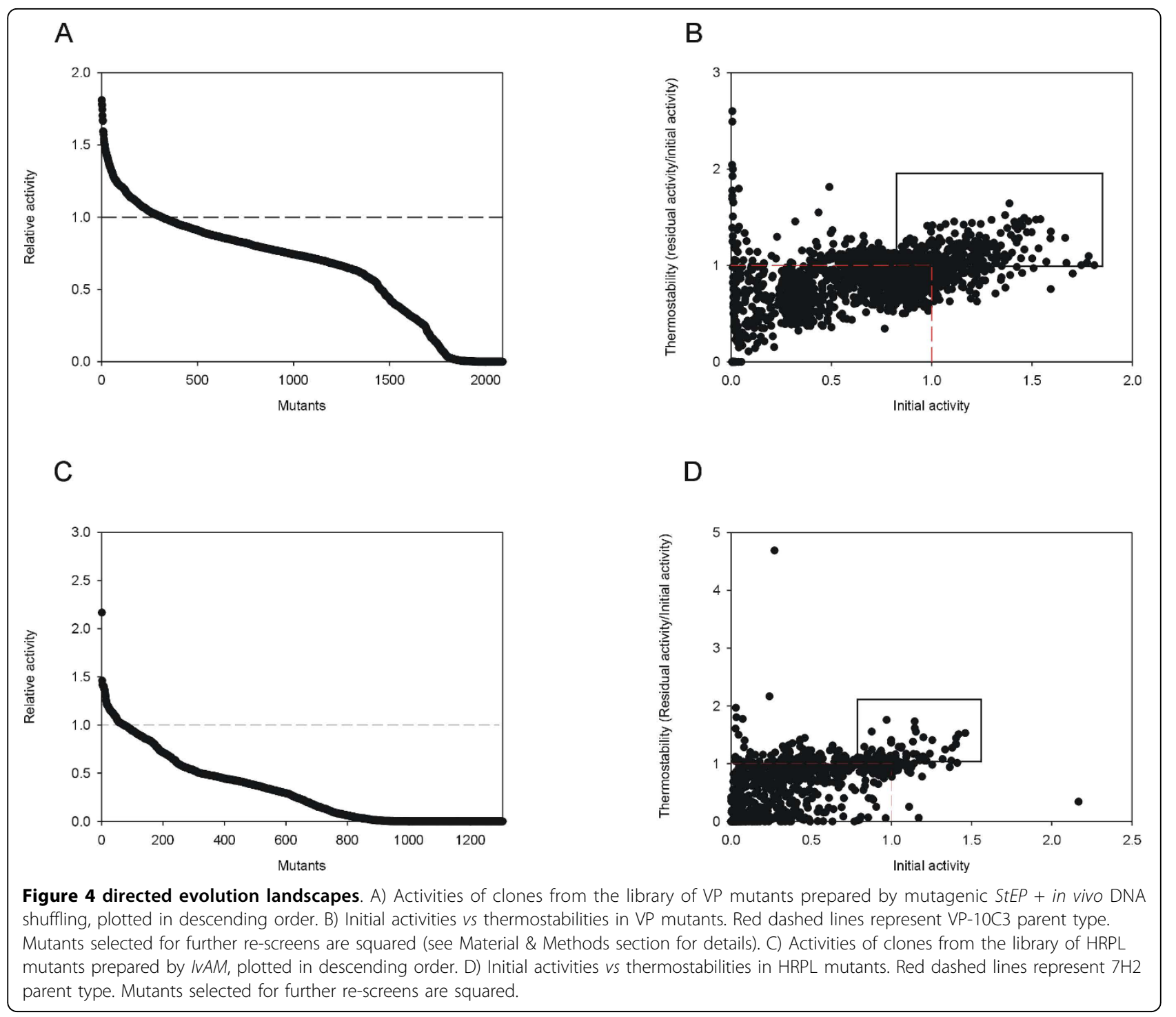

fold $v s$ best parent type, 10C3 mutant). It is noteworthy that the best thermostable variant (24E10 mutant, with 1.23-fold better stability than 10C3) contains the same four mutations as R4 plus mutation G330R, which logically is responsible for the improvement in the thermostability. Mutation G330R shifted the $\mathrm{T}_{50} 2.2^{\circ} \mathrm{C}$, from $60.5^{\circ} \mathrm{C}$ to $62.7^{\circ} \mathrm{C}$ (Fig. 6A), but decreased the activity of the variant almost 0.77 fold. Indeed, the improvement in protein stability came at the cost of reducing activity (the well known tradeoff that usually appears between activity and stability for many single point mutations). However, the recombination method designed for this experiment (mutagenic StEP + in vivo DNA shuffling) made possible to join the four beneficial mutations for the activity which somehow buffered the effect of incorporating the stabilizing mutation G330R, giving rise to an enzyme with similar activity to the parent types but more thermostable. Mutation G330R is placed at the C-terminal tail of VP, a controversial region that, although is not involved in VP oxidation of $\mathrm{Mn}^{2+}$ as initially suggested for the C-tail of Phanerochaete chrysosporium MnP [41], presents a high mobility that prevented to fix the position of the last 12 residues when the VP crystal structure was solved (PDB entry 2BOQ). This highly-mobile region could contribute to the thermal denaturation of the protein, and it is possible to speculate that the introduction of an arginine side-chain at position-330 could stabilize the region, and the whole VP protein, by establishing some new interaction/s, whose nature cannot be determined due to the lack of valuable crystallographic data for the C-terminal tail of VP.

HRPL-library was generated by IvAM from $7 \mathrm{H} 2$ mutant, the best variant of the $5^{\text {th }}$ round of evolution for total activity enhancement (Fig. 7). $7 \mathrm{H} 2$ was a good 


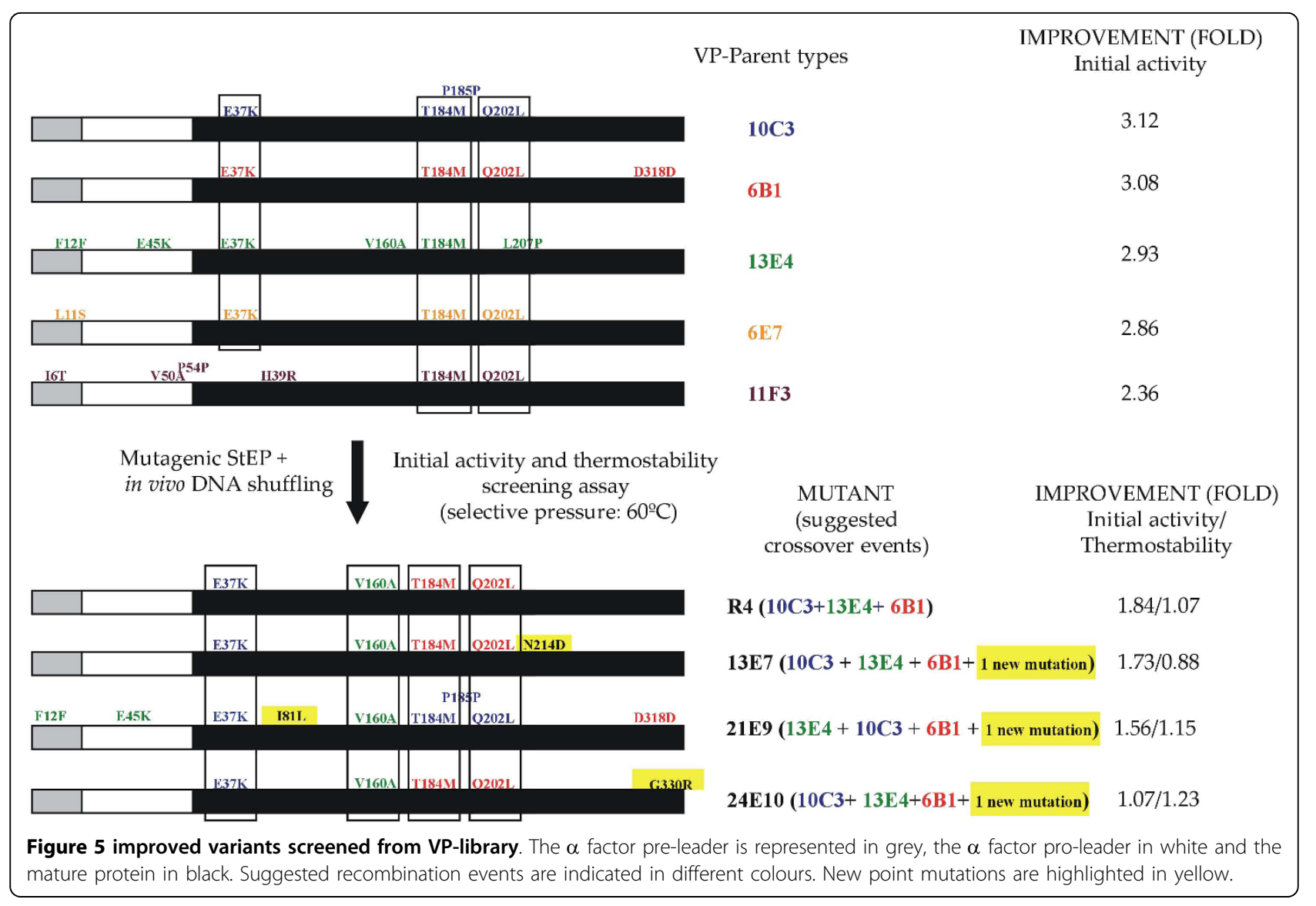

candidate to improve the thermostability: during the former round of evolution by mutagenic in vivo DNA-shuffling, although its activity was improved almost 5 -fold (achieving $1000 \pm 24$ ABTS-Units/L), its stability diminished considerably, with a decrease in the $\mathrm{T}_{50}$ of $\sim 5^{\circ} \mathrm{C} v s$ $1 \mathrm{D} 11$ and $11 \mathrm{~A} 2$ parent types (Fig. 6B). As main consequence of the drop in the $\mathrm{T}_{50}, 7 \mathrm{H} 2$ was unstable during long-term storage (loosing about $30 \%$ of its activity after 15 days at $4^{\circ} \mathrm{C}$ ). In the context of directed evolution experiments, this effect is not surprising and there are many examples in literature about falls in stability because of introducing beneficial but destabilizing mutations for enhanced activity [3]. Taking into account that $7 \mathrm{H} 2$ was created from a single crossover event between 1D11 and 11A2 variants (Fig. 7), and that both parent types shares similar $\mathrm{T}_{50}$ values $\left(73.7\right.$ and $73.3^{\circ} \mathrm{C}$ respectively, Fig. 6B) it became clear that the only new mutation incorporated in $7 \mathrm{H} 2$ (F454S) was responsible for the dramatic drop in the $\mathrm{T}_{50}$. The mutation was mapped in a model based on the Trametes trogii laccase (97\% identity) crystal structure [34]. Phe454 is placed in a region close to the T1 cooper site, the place where the reducing substrate binds. The change from Phe to Ser at this position seems to disrupt several interactions with neighboring residues, which probably affects stability. Best mutants of the thermostability cycle where sequenced (Table 1) and in all cases new mutations at the pre- or pro-leader were introduced benefiting the secretion levels by yeast (with improvement in total activities ranging from 1800 to 500 ABTS-Units/L). The best thermostable mutant (16B10 variant) displayed 1.6 -fold better stability than $7 \mathrm{H} 2$, shifting its $\mathrm{T}_{50}$ value over $3^{\circ} \mathrm{C}$, but at the cost of reducing its activity by half (Fig. 6B and Fig. 7). In spite of the fact that IVAM method takes advantage of mixing different mutational profiles created by polymerases with broad differences in mutational bias (Table 1), the constraint of starting from only one single parent type hindered to find appropriate crossovers events (as happened in VPlibraries) that otherwise could have helped to prevent the detrimental effect on activity of introducing stabilizing mutations. 16B10 harbours 4 mutations in mature protein (two synonymous). Mutations A361T and S482L are placed at the surface of the protein, close to the C-end. Both mutations are at least $21 \AA$ from the nearest catalytic copper atom (Table 1, Fig. 8). Ala361 is located in a loop and interacts with Leu364 by a hydrogen bond. The change from Ala to Thr at position 361, kept the mentioned interaction and allowed one additional hydrogen 


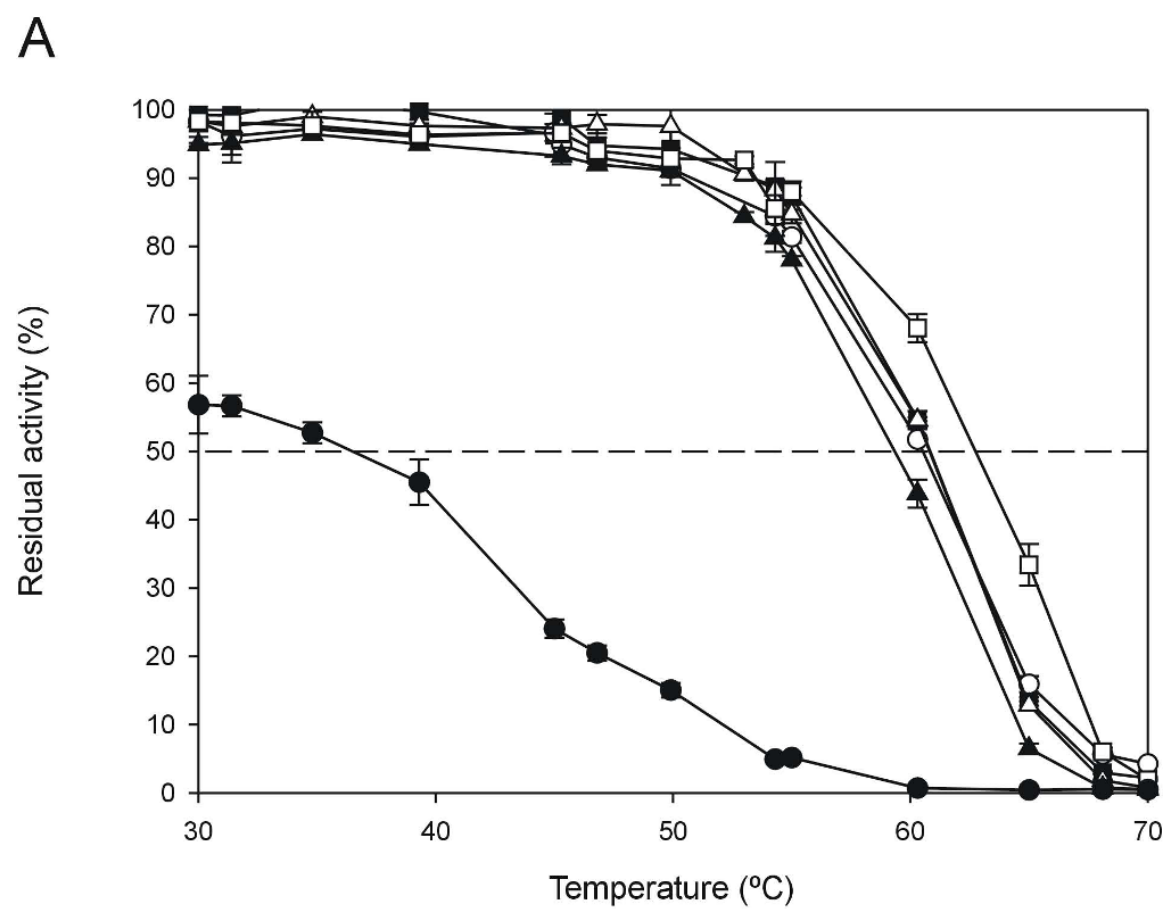

B

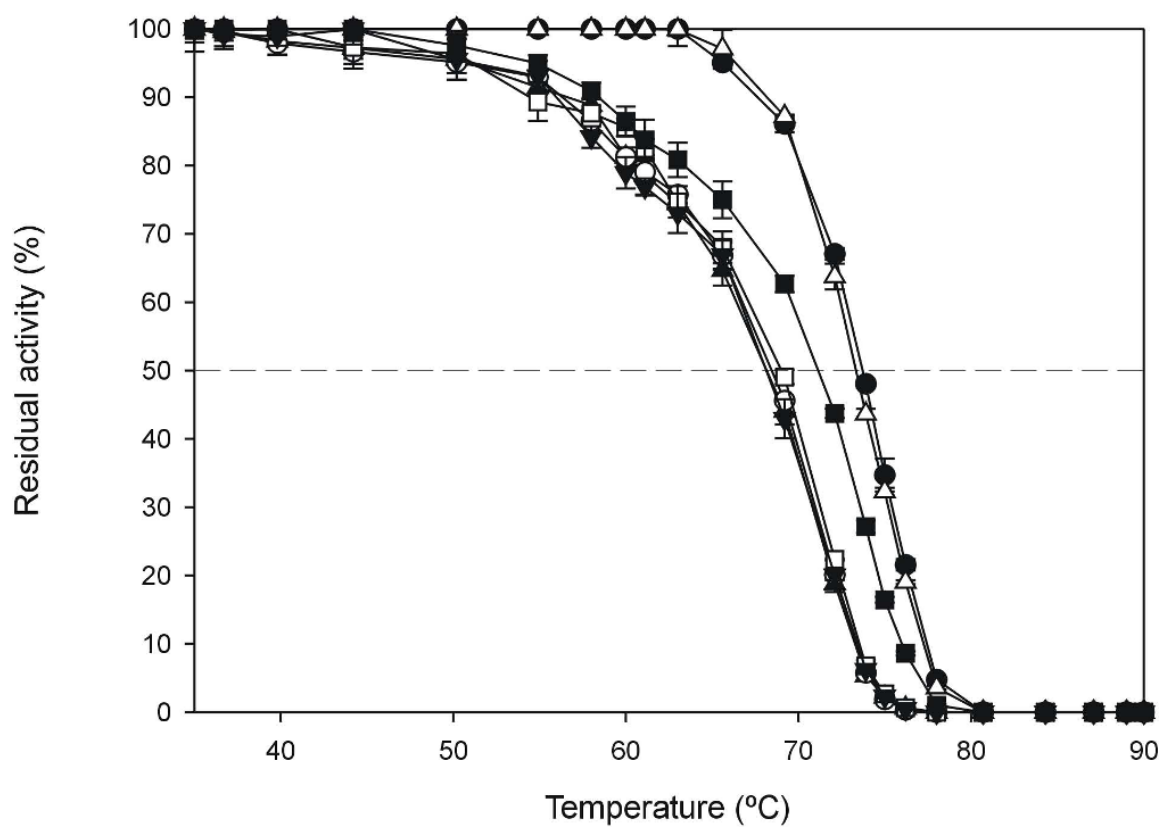

Figure 6 A) $T_{50}$ for VP parent types and different mutants of the evolutionary process. White squares, 24E10 mutant; black triangles, R4 mutant; black squares, $10 C 3$ mutant (best parent type from $3^{\text {rd }}$ generation); white circles, best parent type from $2^{\text {nd }}$ generation; white triangles, best parent type from $1^{\text {st }}$ generation; black circles, native VP expressed in E. coli after in vitro refolded from inclusion bodies. B) $T_{50}$ for HRPL parent types and mutants of the in vitro evolution. Black circle, 1D11 mutant ( $4^{\text {th }}$ generation); white triangle, $11 \mathrm{~A} 2$ mutant (4 $4^{\text {th }}$ generation); black triangle, $7 \mathrm{H} 2$ mutant ( $5^{\text {th }}$ generation); white circle, $6 \mathrm{C} 8$ mutant ( $6^{\text {th }}$ generation); white square, $5 \mathrm{H} 12$ mutant ( $6^{\text {th }}$ generation); black down triangle, $10 \mathrm{~B} 1$ mutant $\left(6^{\text {th }}\right.$ generation); black square, $16 \mathrm{~B} 10$ mutant $\left(6^{\text {th }}\right.$ generation). Each point, including the standard deviation, comes from three independent experiments. 


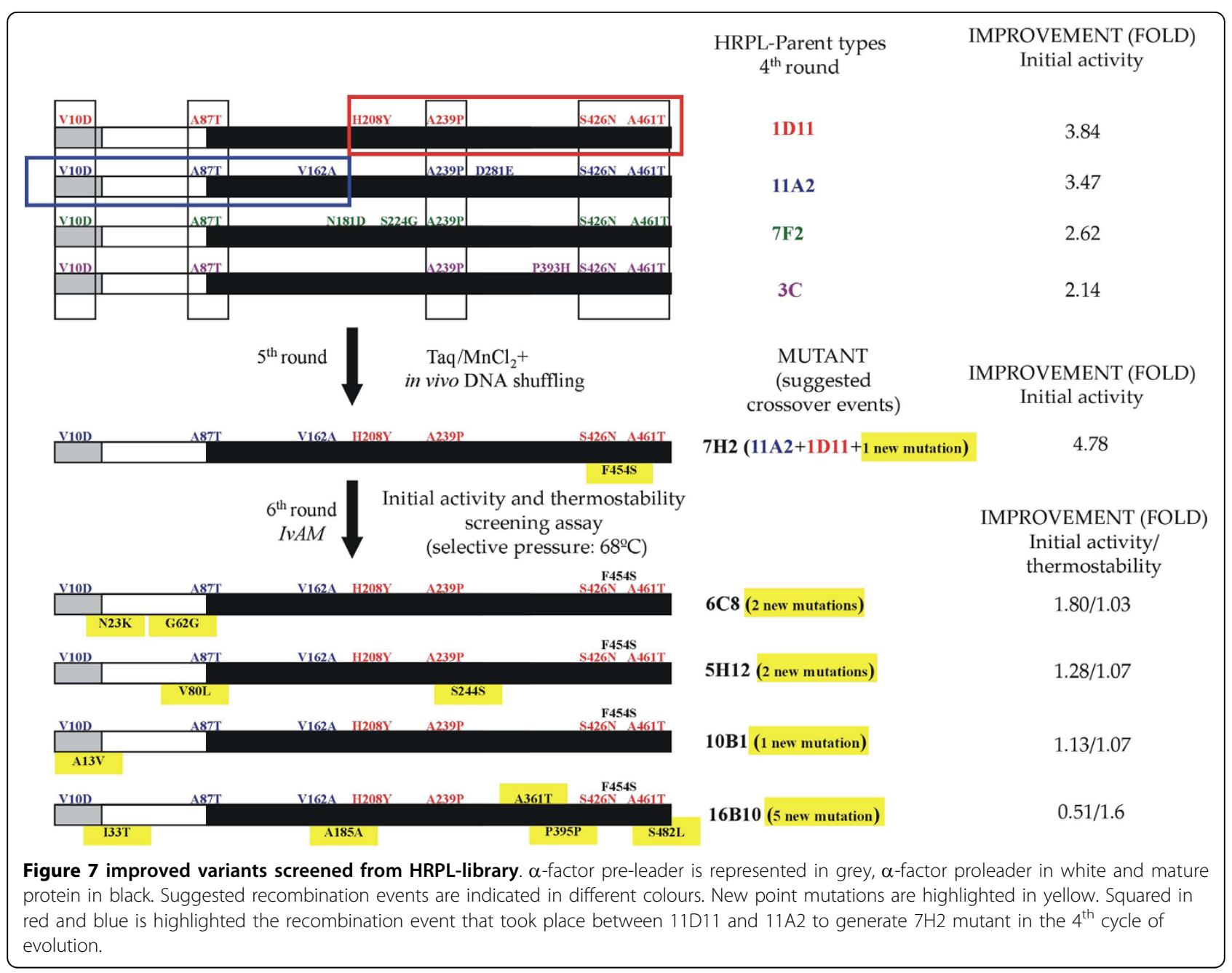

Table 1 HRPL selected mutants generated by IVAM

\begin{tabular}{|c|c|c|c|c|c|c|c|}
\hline Mutant & $\begin{array}{l}\text { Amino acid } \\
\text { Substitution }\end{array}$ & $\begin{array}{l}\text { Nucleotide } \\
\text { change }\end{array}$ & $\begin{array}{l}\text { Mutation } \\
\text { type }\end{array}$ & Location & $\begin{array}{c}\text { Secondary structure } \\
\text { motif }\end{array}$ & $\begin{array}{c}\text { Distance to the T1 } \\
\text { Site }(\AA)\end{array}$ & $\begin{array}{c}\text { Distance to the T2/ } \\
\text { T3 (A) }\end{array}$ \\
\hline \multirow[t]{2}{*}{$6 C 8$} & N23K & AAC69AAA & TV & Pro-leader & & & \\
\hline & $\underline{\mathrm{G} 62 \mathrm{G}}$ & ${ }_{6} \mathrm{GGG} 186 \mathrm{GGA}_{11}$ & Ts & Pro-leader & & & \\
\hline \multirow[t]{2}{*}{$5 \mathrm{H} 12$} & V80L & GTA238CTA & TV & Pro-leader & & & \\
\hline & $\underline{\mathrm{S} 244 \mathrm{~S}}$ & ${ }_{8} \mathrm{TCG}_{1005 \mathrm{TCC}_{14}}$ & Tv & $\begin{array}{l}\text { Mature } \\
\text { protein } \\
\end{array}$ & & & \\
\hline \multirow[t]{3}{*}{ 10B1 } & A13V & GCA38GTA & Ts & Pre-leader & & & \\
\hline & $133 \mathrm{~T}$ & ATT98ACT & Ts & Pro-leader & & & \\
\hline & $\underline{\mathrm{A} 185 \mathrm{~A}}$ & ${ }_{21} \mathrm{GCT} 828 \mathrm{GCC} 13$ & Ts & $\begin{array}{l}\text { Mature } \\
\text { protein }\end{array}$ & & & \\
\hline \multirow[t]{3}{*}{$16 \mathrm{~B} 10$} & $\mathrm{~A} 361 \mathrm{~T}$ & GCG1354ACG & Ts & $\begin{array}{l}\text { Mature } \\
\text { protein }\end{array}$ & loop & 23 & 21 \\
\hline & $\underline{\mathrm{P} 395 \mathrm{P}}$ & ${ }_{7} \mathrm{CCC}_{1458 C C T_{13}}$ & Ts & $\begin{array}{l}\text { Mature } \\
\text { protein }\end{array}$ & & & \\
\hline & S482L & TCG1718TTG & Ts & $\begin{array}{l}\text { Mature } \\
\text { protein }\end{array}$ & sheet & 34 & 24 \\
\hline
\end{tabular}

Synonymous mutations are underlined; nucleotide change is highlighted in bold; subscript numbers on codons indicate codon usage. Tv, transversions; Ts, transitions. 


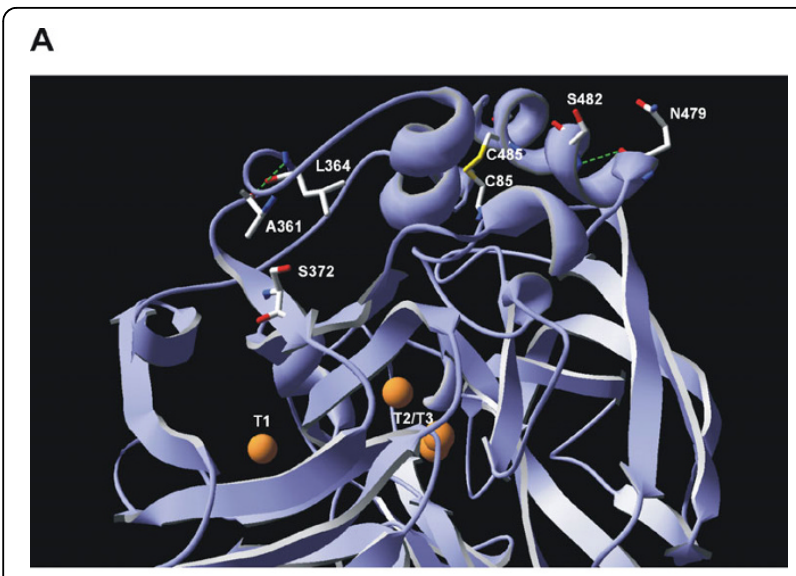

\section{B}

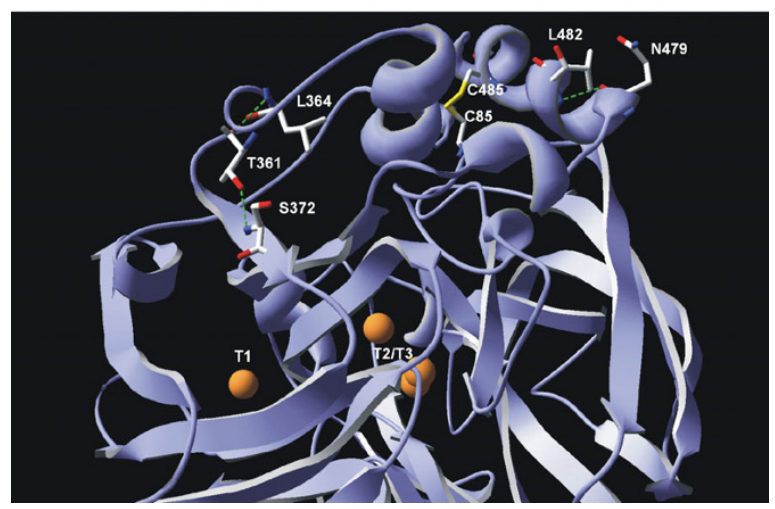

Figure 8 location and surroundings of stabilizing mutations in HRPL. A) parent type. B) 16 B10 variant. The orange spheres represent $\mathrm{Cu}$ atoms. bond with Ser372 placed in a beta-sheet. This structural reinforcement upon mutation might confer rigidity to the protein enhancing its stability. Mutation S482L is in the neighbourhood of the disulfide bridge between Cys485 and Cys85. Ser482 is part of a $\alpha$-helix and establishes a hydrogen bond with Gln479 of same motif. Inspection of the protein model suggests that the S482L mutation does not interrupt such a bond. The change of a polar amino acid by a bigger hydrophobic one might allow establishing hydrophobic interactions with surrounding residues which may further stabilize the protein structure at this region.

\section{Conclusions}

In summary, S. cerevisiae is a valuable cell factory for the directed evolution of ligninolytic enzymes for thermostability and taking together, the VP and the HRPL evolved variants share several common features. First, the thermostability improvements obtained for both VP and HRPL systems are especially significant near the enzyme inactivation temperatures: the best VP (24E10) showed $\sim 30 \%$ of its maximal activity at $65^{\circ} \mathrm{C}$ (3-fold more than the initial VP) and the best laccase (16B10) up to $40 \%$ of its maximal activity at $72^{\circ} \mathrm{C}$ (over 10-fold more than the corresponding parent type). Second, an apparently inherent tradeoff between activity and stability appeared in both enzymes for different amino acid substitutions. Although not physically incompatible, in general protein scaffolds activity and thermostability tend to act as communicating vessels and the laboratory design of any of them usually come at the cost of its counterpart. For protein engineers, to find single mutations which improve both properties simultaneously is extremely difficult. In nature, stability is under selection just in the case that it is required for biochemical function, hence mutations which join activity and stability are rare taking into account the genetic drift and that a selective pressure towards both features at the same time is not frequently exerted. It has been reported that in principle is easier to evolve thermostability while keeping activity than vice versa, although recent research indicates that evolving activity while maintaining stability can be accomplished as well $[1,39]$. We have demonstrated that the generation of complex crossover events along with the introduction of new mutations facilitates the improvement in the stability of ligninolytic oxidoreductases buffering the drops on their activities. In the evolutionary scenario, the recombination methods described in this work for the generation of diversity along with the screening assay engineered for this specific task can be valuable tools not only to tailor thermostable ligninolytic oxidoreductases but also other enzymatic systems.

\section{Abbreviations}

ABTS: 2,2'-azino-bis (3 ethylbenzothiazoline 6 sulfonic acid); DMSO: dimethylsulfoxide; HRPL: High Redox Potential Laccases; IvAM: In vivo Assembly of Mutant libraries with different mutational spectra; RA/IA: Residual Activity/Initial Activity; StEP: Staggered Extension Process; $T_{50}$ : Temperature at which the enzyme loses $50 \%$ of its activity following incubation for 10 minutes; VP: Versatile Peroxidase.

\section{Acknowledgements}

Authors truly thank Prof. Ramón Santamaria from Salamanca University for providing PM1 laccase gene. This material is based upon work funded by National Projects CCG08-CSIC/PPQ-3706 and CSIC 2008801033; and EU Projects NMP4-SL-2009-229255 and NMP2-CT-2006-026456. D.M. thanks the CSIC for a JAE contract.

\section{Author details}

${ }^{1}$ Department of Biocatalysis, Institute of Catalysis, CSIC, 28049 Madrid, Spain. ${ }^{2}$ Centro de Investigaciones Biológicas, CSIC, 28040 Madrid, Spain.

\section{Authors' contributions}

The PhD students EGR and DM carried out all the experiments on VP and HRPL respectively under the supervision of MA. ATM provided background on VP and co-supervised EGR. MA wrote the first draft which was revised by ATM and AB. MA coordinated the final version of the paper, which was read and approved by all authors.

\section{Competing interests}

The authors declare that they have no competing interests. 
Received: 3 December 2009 Accepted: 18 March 2010

Published: 18 March 2010

\section{References}

1. Bloom JD, Labthavikul ST, Otey CR, Arnold FH: Protein stability promotes evolvability. Proc Natl Acad Sci USA 2006, 103:5869-5874.

2. Bloom JD, Wilke CO, Arnold FH, Adami C: Stability and the evolvability of function in a model protein. Biophys $J$ 2004, 86:2758-2764.

3. Bloom JD, Arnold FH: In the light of directed evolution: Pathways of adaptive protein evolution. Proc Natl Acad Sci USA 2009, 106:9995-10000

4. Watanabe K, Ohkuri T, Yokobori S, Yamagishi A: Designing thermostable proteins: Ancestral mutants of 3-isopropylmalate dehydrogenase designed by using a phylogenetic tree. J Mol Biol 2006, 355:664-674

5. Ogino $\mathrm{H}$, Ishikawa $\mathrm{H}$ : enzymes which are stable in the presence of organic solvents. J Biosci Bioeng 2001, 91:109-116.

6. Arnold FH: Engineering enzymes for nonaqueous solvents. Trends Biotechnol 1990, 8:244-249.

7. Suen WC, Zhang NY, Xiao L, Madison V, Zaks A: Improved activity and thermostability of Candida antarctica lipase B by DNA family shuffling. Protein Eng 2004, 17:133-140.

8. Johannes TW, Woodyer RD, Zhao HM: Directed evolution of a thermostable phosphite dehydrogenase for $\mathrm{NAD}(\mathrm{P}) \mathrm{H}$ regeneration. Appl Environ Microb 2005, 71:5728-5734.

9. Arnold FH, Georgiou G: Directed Enzyme Evolution: screening and selection methods. Methods in Molecular Biology Humana Press, Totowa, New Jersey 2003, 231.

10. Reetz MT, Carballeira JD, Vogel A: Iterative saturation mutagenesis on the basis of $\mathrm{B}$ factors as a strategy for increasing protein thermostability. Angew Chem Int Ed 2006, 45:7745-7751.

11. Bommarius AS, Broering JM, Chaparro-Riggers JF, Polizzi KM: Highthroughput screening for enhanced protein stability. Curr Opin Biotech 2006, 17:606-610.

12. López Camacho C, Salgado J, Lequerica UL, Madarro A, Ballestar E, Franco L, Polaina J: Amino acid substitution enhancing thermostability of Bacillus polymixa beta-glucosidase A. Biochem J 1996, 314:833-838

13. Miyazaki K, Takenouchi M, Kondo H, Noro N, Suzuki M, Tsuda S: Thermal stabilization of Bacillus subtilis family-11 xylanase by directed evolution. $J$ Biol Chem 2006, 281:10236-10242.

14. Giver L, Gershenson A, Freskgard PO, Arnold FH: Directed evolution of a thermostable esterase. Proc Natl Acad Sci USA 1998, 95:12809-12813.

15. Arnold FH, Giver L, Gershenson A, Zhao HM, Miyazaki K: Directed evolution of mesophilic enzymes into their thermophilic counterparts. Proc Nat Acad Sci USA 1999, 870:400-403.

16. Hao J, Berry A: A thermostable variant of fructose bisphosphate aldolase constructed by directed evolution also shows increased stability in organic solvents. Protein Eng 2004, 17:689-697.

17. Morawski B, Quan S, Arnold FH: Functional expression and stabilization of horseradish peroxidase by directed evolution in Saccharomyces cerevisiae. Biotechnol Bioeng 2001, 76:99-107.

18. Salazar O, Cirino PC, Arnold FH: Thermostabilization of a cytochrome P450 peroxygenase. Chem Bio Chem 2003, 4:891-893.

19. Reading NS, Aust SD: Engineering a disulfide bond in recombinant manganase peroxidase results in increased thermostability. Biotechnol Progr 2000, 16:326-333.

20. Sun LH, Petrounia IP, Yagasaki M, Bandara G, Arnold FH: Expression and stabilization of galactose oxidase in Escherichia coli by directed evolution. Protein Eng 2001, 14:699-704.

21. Kunamneni A, Camarero S, García-Burgos C, Plou FJ, Ballesteros A, Alcalde M: Engineering and Applications of fungal laccases for organic synthesis. Microb Cell Fact 2008, 7.

22. Alcalde M, Ferrer M, Plou FJ, Ballesteros A: Environmental biocatalysis: from remediation with enzymes to novel green processes. Trends Biotechnol 2006, 24:281-287.

23. Martínez AT, Ruiz-Dueñas FJ, Martínez MJ, del Río JC, Gutiérrez A: Enzymatic delignification of plant cell wall: from nature to mill. Curr Opin Biotechnol 2009, 20:348-357.

24. Alcalde M: Laccase: biological functions, molecular structure and industrial applications. Industrial Enzymes: structure, functions and applications New York, SpringerPolaina J, MacCabe AP 2007, 459-474.

25. Riva S: Laccases: blue enzymes for green chemistry. Trends Biotechnol 2006, 24:219-226.
26. Ruiz-Dueñas FJ, Morales M, García E, Miki Y, Martínez MJ, Martínez AT: Substrate oxidation sites in versatile peroxidase and other basidiomycete peroxidases. J Exp Bot 2009, 60:441-452.

27. Ruiz-Duenas FJ, Martinez MJ, Martinez AT: Heterologous expression of Pleurotus eryngii peroxidase confirms its ability to oxidize $\mathrm{Mn}^{2+}$ and different aromatic substrates. Appl Environ Microbiol 1999, 65:4705-4707.

28. Coll PM, Tabernero C, Santamaria R, Perez P: Characterization and structural analysis of the laccase I gene from the newly isolated ligninolytic basidiomycete PM1 (CECT 2971). Appl Environ Microbiol 1993, 59:4129-4135.

29. García E, Martínez MJ, Dueñas J, Martínez AT, Alcalde M: High redox potential peroxidases engineered by directed evolution. Patent $n^{\circ}$ 200930157. Spain 2009.

30. Zhao HM, Giver L, Shao ZX, Affholter JA, Arnold FH: Molecular evolution by staggered extension process (StEP) in vitro recombination. Nature Biotech 1998, 16:258-261.

31. Okkels JS: In vivo gene shuffling in yeast: a fast and easy method for directed evolution of enzymes. Enzyme Functionality: Design, Engineering and Screening Marcel Dekker, Inc. New YorkSvendsen A 2004, 413-424.

32. Zumárraga M, Camarero S, Shleev S, Martínez-Arias A, Ballesteros A, Plou FJ, Alcalde $\mathrm{M}$ : Altering the laccase functionality by in vivo assembly of mutant libraries with different mutational spectra. Proteins 2008, 71:250-260.

33. Zumárraga M, Domínguez CV, Camarero S, Shleev S, Polaina J, MartínezArias A, Ferrer ML, de Lacey A, Fernández V, Ballesteros A, Plou FJ, Alcalde M: Combinatorial Saturation Mutagenesis of the Myceliophthora thermophila laccase T2 mutant: the connection between the C-terminal plug and the conserved 509VSG511 tripeptide. Comb Chem High T Scr 2008, 11:807-816.

34. Matera I, Gullotto A, Tilli S, Ferraroni M, Scozzafava A, Briganti F: Crystal structure of the blue multicopper oxidase from the white-rot fungus Trametes trogii complexed with $p$-toluate. Inorg Chim Acta 2008, 361:4129-4137.

35. Shuster JR: Gene expression in yeast: protein secretion. Curr Opin Biotechnol 1991, 2:685-690.

36. Tracewell CA, Arnold FH: Directed ezyme evolution: climbing fitness peaks one amino acid at a time. Curr Opin Chem Biol 2009, 13:3-9.

37. Cherry JR, Lamsa MH, Schneider P, Vind J, Svendsen A, Jones $A$, Pedersen AH: Directed Evolution of a fungal peroxidase. Nature Biotech 1999, 17:379-384.

38. Bulter T, Alcalde M, Sieber V, Meinhold P, Schlachtbauer C, Arnold FH: Functional expression of a fungal laccase in Saccharomyces cerevisiae by directed evolution. Appl Environ Microb 2003, 69:987-995.

39. Zumárraga M, Bulter T, Shleev S, Polaina J, Martínez-Arias A, Plou FJ, Ballesteros A, Alcalde M: In vitro evolution of a fungal laccase in high concentrations of organic cosolvents. Chem Biol 2007, 14:1052-1064.

40. Alcalde M, Zumárraga M, Polaina J, Ballesteros A, Plou FJ: Combinatorial saturation mutagenesis by in vivo overlap extension for the engineering of fungal laccases. Comb Chem High T Scr 2006, 9:719-727.

41. Ruiz-Dueñas FJ, Morales M, Pérez-Boada M, Choinowski T, Martínez MJ, Piontek K, Martínez AT: Manganese oxidation site in Pleurotus eryngii versatile peroxidase: A site-directed mutagenesis, kinetic, and crystallographic study. Biochemistry 2007, 46:66-77.

doi:10.1186/1475-2859-9-17

Cite this article as: García-Ruiz et al.: Evolving thermostability in mutant libraries of ligninolytic oxidoreductases expressed in yeast. Microbial Cell Factories 2010 9:17. 